\title{
Oscillatory Behavior in Methane Combustion: Influence of the Operating Parameters
}

\author{
M. Lubrano Lavadera, ${ }^{* \dagger \odot}$ Y. Song, ${ }^{\ddagger}$ P. Sabia, ${ }^{\dagger}$ O. Herbinet, ${ }^{\ddagger}$ M. Pelucchi, ${ }^{\S}$ A. Stagni, ${ }^{\S}$ T. Faravelli, ${ }^{\S}$ \\ F. Battin-Leclerc, ${ }^{\ddagger 0}$ and M. de Joannon ${ }^{\dagger}$ \\ ${ }^{\dagger}$ Istituto di Ricerche sulla Combustione, Consiglio Nazionale delle Ricerche (CNR), Piazzale Tecchio 80, 80125 Napoli, Italy \\ "Laboratoire Réactions et Génie des Procédés, Centre National de la Recherche Scientifique (CNRS), Université de Lorraine, 1 Rue \\ Grandville, BP 20451, 54001 Nancy, France \\ ${ }^{\S}$ Dipartimento di Chimica, Materiali e Ingegneria Chimica, Politecnico di Milano, Piazza Leonardo da Vinci 32, 20133 Milano, Italy

\section{Supporting Information}

\begin{abstract}
The influence of the main process parameters on the oscillatory behavior of methane oxidation was analyzed in conditions relevant for low-temperature combustion processes. The investigation was performed by means of direct comparisons between experimental measurements realized in two jet-stirred flow reactors used at atmospheric pressure. With the operating conditions of the two systems coupled, wide ranges of the inlet temperature (790-1225 K), equivalence ratio ( 0.5 $<\Phi<1.5)$, methane mole fraction $\left(X_{\mathrm{CH}_{4}}\right.$ from 0.01 to 0.05$)$, bath gases (i.e., $\mathrm{He}, \mathrm{N}_{2}, \mathrm{CO}_{2}$, or $\mathrm{H}_{2} \mathrm{O}$ ) and different overall mixture dilution levels were exploited in relation to the identification of oscillatory regimes. Although the reference systems mainly differ in thermal conditions (i.e., heat exchange to the surroundings), temperature measurements suggested that the oscillatory phenomena occurred when the system working temperature accessed a well-identifiable temperature range. Experimental results were simulated by means of a detailed kinetic scheme and commercial codes developed for complex chemistry processes. Simulations were also extended considering systems with different heat losses to the surroundings, thus passing from adiabatic to isothermal systems. Results highlighted the kinetic nature of the dynamic behavior. Because predictions were consistent with experimental tests, further numerical analyses were realized to identify the kinetics responsible for the establishment of oscillatory phenomena. Temperature oscillations were predicted for a significant reactor working temperature range, where oxidation and recombination kinetic routes, involving carbon $\mathrm{C}_{1-2}$ species as well as reactions of the $\mathrm{H}_{2} / \mathrm{O}_{2}$ sub-scheme, become competitive, thus boosting limit cycle behaviors. Oscillatory phenomena cease when the system working temperatures exceed characteristic threshold values with the promotion of faster oxidation routes that diminish the inhibiting effects of recombination reactions.
\end{abstract}

\section{INTRODUCTION}

Despite much progress in the application of new combustion concepts to practical systems, such as low-temperature combustion (LTC) processes, there remains unresolved issues on the stabilization of the oxidation process. ${ }^{1}$ A problem related to LTC processes is the susceptibility to thermokinetic oscillations, originating from nonlinear dependence of relevant variables.

Such instabilities may hamper the large-scale implementation of advanced combustion processes. ${ }^{2}$ Therefore, there is a need for a fundamental understanding of critical parameters that promote instabilities.

To properly investigate oscillatory phenomena, open systems are necessary. A very useful tool for the observation of combustion regimes as a function of the operating parameters is the well-stirred reactor (WSR). In this device, in contrast to chemical reactions occurring in a closed vessel that proceed to a unique point of thermodynamic equilibrium, it is possible to achieve a multiplicity of permanent steady states far from equilibrium as well as sustained oscillations that may also be preserved indefinitely.

A large amount of literature exists on the analysis of dynamic phenomena taking place in open well-stirred reactors. For example, such reactors have been widely used to investigate oscillatory cool flames and complex ignition phenomena under non-adiabatic conditions for high-molecular-weight organic compounds at low temperature $(T<850 \mathrm{~K})$, as a result of thermal feedback coupled to complex kinetics. ${ }^{3-6}$ Scientific interpretations of these phenomena date back several decades because modeling of the low-temperature oxidation of hydrocarbons is relevant to the onset of "knock" in sparkignition (SI) engines or the ignition in diesel fuels. ${ }^{7-9}$ Recently, the same oscillatory behavior was also found for dimethyl ether (DME) between 530 and $650 \mathrm{~K}^{10}$

Oscillatory behaviors have also been recognized for lowmolecular-weight fuels, such as hydrogen ${ }^{11-17}$ or hydrogen and carbon monoxide mixtures. ${ }^{18-20}$ Notwithstanding exothermic contributions, the oscillations of such mixtures originate from a kinetic interaction driven by the competitive elementary reactions $\mathrm{H}+\mathrm{O}_{2}=\mathrm{OH}+\mathrm{O}$ and $\mathrm{H}+\mathrm{O}_{2}+\mathrm{M}=\mathrm{HO}_{2}+\mathrm{M}$.

Special Issue: SMARTCATs COST Action

Received: March 21, 2018

Revised: May 26, 2018

Published: June 20, 2018 
For the latter, in fact, the rate of recombination waxes and wanes according to the third body efficiencies of species in the vessel.

Other experimental ${ }^{2,21,22}$ and numerical ${ }^{23,24}$ studies have focused on methane ignition and oxidation under moderate or intense low-oxygen dilution (MILD) combustion operative conditions in flow reactors at atmospheric pressure. These studies highlighted the onset of non-isothermal oscillatory regimes similar to cool-flame oscillations but at higher temperatures $(1000-1300 \mathrm{~K})$. Sabia et al. ${ }^{25}$ extended the studies by de Joannon et al. ${ }^{2,21}$ adding $\mathrm{H}_{2}$ to $\mathrm{CH}_{4} / \mathrm{O}_{2} / \mathrm{N}_{2}$ mixtures. These studies showed that $\mathrm{H}_{2}$ can reduce the parameter space where oscillations were detected with respect to methane mixtures. de Joannon et al. ${ }^{2,21}$ and Sabia et al. ${ }^{22,25}$ identified different kinetic routes promoted by high inlet temperatures and highly diluted mixtures with respect to conventional flames. In particular, they pointed out that the competition between termolecular recombination reactions and branching reactions is crucial for the appearance of these regimes. Wada et al. ${ }^{24}$ added that a key reaction pathway for the onset of oscillations is the route that converts $\mathrm{CH}_{3}$ to $\mathrm{CH}_{2} \mathrm{O}$. At a low temperature, $\mathrm{CH}_{3}$ is oxidized to $\mathrm{CH}_{3} \mathrm{O}$ and $\mathrm{CH}_{3} \mathrm{O}_{2}$, which, in turns, react to form $\mathrm{CH}_{2} \mathrm{O}$, while at intermediates, one $\mathrm{CH}_{3}$ produces directly $\mathrm{CH}_{2} \mathrm{O}$ by reacting with $\mathrm{HO}_{2}$ radicals.

All of these previous studies ${ }^{2,21-25}$ claim that oscillations have a thermokinetic nature; thus, they originate from a balance between the heat released by chemical reactions and the heat loss to the surroundings.

On the other hand, Sabia et al. ${ }^{26}$ have recently found that dynamic behaviors can also be numerically obtained under adiabatic conditions; thus, they highlighted the kinetic aspect of such phenomena.

Another process, which received considerable attention, is the thermal oxidative coupling of methane (OCM). It is generally accepted that a homogeneous coupling of the methyl radical, producing ethane, becomes important when the temperature is between 1000 and $1300 \mathrm{~K},{ }^{27}$ which is the same temperature range in which non-isothermal oscillatory regimes have been highlighted for methane oxidation. Therefore, a detailed study of methane oscillations can also be used to improve the OCM process.

Recently, Bagheri et al. ${ }^{28}$ explored thermochemical oscillations of methane from a kinetic modeling perspective, also focusing on the effect of different dilution gases $\left(\mathrm{N}_{2}, \mathrm{H}_{2} \mathrm{O}\right.$, and $\mathrm{CO}_{2}$ ) in promoting or inhibiting such instabilities. The authors found that the variations of heat capacity associated with the different bath gases directly impact the oscillation characteristics. On the other hand, the authors noted that, in WSR isothermal studies available in the literature, oscillations were not reported; however, an attempt at modeling these cases revealed the presence of cyclic oscillatory behaviors.

Given this background, the objective of the current work is to extend the fundamentals of methane combustion stability under well-stirred flowing conditions, with particular emphasis on the physical and chemical factors that control the oscillatory phenomenon. To seek the means to interpret events in a wider range of external parameters, experimental tests were carried out in two jet-stirred flow reactors (JSFRs), characterized by different heat releases. Oscillation onset, waveform, amplitude, and frequency were characterized as a function of the (1) inlet temperature, (2) equivalence ratio, (3) residence time, (4) methane mole fraction/mixture dilution level, and (5) chemical nature of the bath gas $\left(\mathrm{He}, \mathrm{N}_{2}, \mathrm{CO}_{2}\right.$, or $\left.\mathrm{H}_{2} \mathrm{O}\right)$, at atmospheric pressure.

The interest in the effects of the bath gas is 2-fold: first, for LTC systems, the combustion occurs in the presence of noninert species $\left(\mathrm{CO}_{2}\right.$ or $\left.\mathrm{H}_{2} \mathrm{O}\right)$ as a result of the strong recirculation of exhausted gases, and second, such species are commonly present in low-calorific-value (LCV) fuels. These species may have a thermal effect (i.e., higher heat capacities) or a kinetic effect, participating directly in bimolecular elementary reactions or as a third body in termolecular reactions with high collisional Chaperon efficiencies. The comparison to mixtures diluted with inert species can reveal the role of $\mathrm{CO}_{2}$ or $\mathrm{H}_{2} \mathrm{O}$ in oxidation processes at lowintermediate temperatures.

Finally, the experimental measurements were supported by extensive numerical analyses of a chosen detailed thermokinetic model to identify the kinetics responsible for the onset and termination of oscillations with respect to operating parameters.

\section{EXPERIMENTAL AND NUMERICAL TOOLS}

Experimental Apparatuses. In the present work, two spherical JSFRs were used: the former is available at the Laboratoire Réactions et Génie des Procédés, Centre National de la Recherche Scientifique (CNRS), Universite de Lorraine (Nancy, France), ${ }^{29}$ while the latter is available at the Istituto di Ricerche sulla Combustione, Consiglio Nazionale delle Ricerche (CNR, Napoli, Italy). ${ }^{2}$ Hereafter, they will be referred as the "Nancy" and "Napoli" reactors. Photos of the two JSFRs are reported in the Supporting Information. They were designed under the same construction rules ${ }^{30,31}$ but conceived to work under different operating conditions (i.e., residence time and mixture composition). The detailed description of the reactors is provided elsewhere. $^{2,29}$

The opportunity to combine the experimental tests from the two facilities implies that a large field of parameters is accessible for an exhaustive investigation of the methane oxidation process. Both the JSFRs consist of a fused silica sphere where reactions take place. Quartz is commonly used to prevent catalytic reactions. The Napoli reactor consists of a sphere of $113 \mathrm{~cm}^{3}$, while the Nancy reactor consists of a sphere of $85 \mathrm{~cm}^{3}$. Fresh reactants enter the reactor through an injection cross (four nozzles, $1 \mathrm{~mm}$ diameter for the Napoli reactor and $0.3 \mathrm{~mm}$ for the Nancy reactor) located at the center of the sphere. The well-mixing condition was verified in the past by means of pulse tracer experiments. ${ }^{32}$ The Napoli reactor behaves as an ideal WSR for residence times $(\tau)$ lower than $0.6 \mathrm{~s}$, while the Nancy reactor behaves as an ideal WSR for residence times $(\tau)$ lower than $10 \mathrm{~s}$. Thus, the experiments were carried out with residence times equal to 0.5 and $2 \mathrm{~s}$, respectively.

In both of the reactors, the total flow is composed by methane, oxygen, and diluent. In the Napoli device, a primary flow, composed of oxygen and diluent, is preheated through a quartz tube located within two semi-cylindrical electrically heated ceramic-fiber-insulated ovens supplied by Watlow Srl, regulated by proportional-integralderivative (PID) controllers. The primary flow subsequently mixes with the secondary flow, composed by fuel and diluent, in a premixing chamber before entering inside the reactor. The reactor is located within two other thermally insulated electrical fiber ovens to minimize heat loss to the surroundings. A recirculation air system provides a homogeneous temperature distribution in the oven. The homogeneity of the reactor external wall temperature is monitored by means of two movable $\mathrm{N}$-type thermocouples.

In the Nancy experiments, the reactor is preceded by an annular preheating zone, in which the temperature of the gases is increased up to the reaction temperature before entering inside the reactor. Then, the premixed mixture enters the reactor. Both the spherical reactor and the annular preheating zone are heated by Thermocoax heating 
Table 1. Experimental Conditions Studied in the JSFRs for $\mathrm{CH}_{4}$ Mixtures ${ }^{a}$

\begin{tabular}{|c|c|c|c|c|c|c|c|c|c|}
\hline case & $\Phi$ & $\tau(\mathrm{s})$ & $X_{\mathrm{CH}_{4}}$ & $X_{\mathrm{O}_{2}}$ & $X_{\mathrm{He}}$ & $X_{\mathrm{N}_{2}}$ & $X_{\mathrm{CO}_{2}}$ & $X_{\mathrm{H}_{2} \mathrm{O}}$ & number of tests \\
\hline $\mathrm{L} 1$ & 0.5 & 0.5 & 0.020 & 0.080 & 0 & 0.900 & 0 & 0 & 22 \\
\hline L2 & 0.5 & 0.5 & 0.020 & 0.080 & 0 & 0 & 0.900 & 0 & 16 \\
\hline L3 & 0.5 & 0.5 & 0.020 & 0.080 & 0 & 0.495 & 0 & 0.405 & 21 \\
\hline L4 & 0.75 & 2 & 0.010 & 0.027 & 0.963 & 0 & 0 & 0 & 10 \\
\hline L5 & 0.75 & 2 & 0.010 & 0.027 & 0 & 0 & 0.963 & 0 & 10 \\
\hline L6 & 0.75 & 2 & 0.025 & 0.067 & 0.908 & 0 & 0 & 0 & 10 \\
\hline L7 & 0.75 & 2 & 0.025 & 0.067 & 0 & 0 & 0.908 & 0 & 10 \\
\hline L8 & 0.75 & 2 & 0.050 & 0.134 & 0.816 & 0 & 0 & 0 & 10 \\
\hline L9 & 0.75 & 2 & 0.050 & 0.134 & 0 & 0 & 0.816 & 0 & 10 \\
\hline $\mathrm{S} 1$ & 1 & 0.5 & 0.033 & 0.067 & 0 & 0.900 & 0 & 0 & 24 \\
\hline S2 & 1 & 0.5 & 0.033 & 0.067 & 0 & 0 & 0.900 & 0 & 15 \\
\hline S3 & 1 & 0.5 & 0.033 & 0.067 & 0 & 0.495 & 0 & 0.405 & 22 \\
\hline S4 & 1 & 2 & 0.010 & 0.020 & 0.970 & 0 & 0 & 0 & 10 \\
\hline S5 & 1 & 2 & 0.010 & 0.020 & 0 & 0 & 0.970 & 0 & 10 \\
\hline S6 & 1 & 2 & 0.025 & 0.050 & 0.925 & 0 & 0 & 0 & 10 \\
\hline S7 & 1 & 2 & 0.025 & 0.050 & 0 & 0 & 0.925 & 0 & 10 \\
\hline S8 & 1 & 2 & 0.050 & 0.100 & 0.850 & 0 & 0 & 0 & 10 \\
\hline S9 & 1 & 2 & 0.050 & 0.100 & 0 & 0 & 0.850 & 0 & 10 \\
\hline $\mathrm{R} 1$ & 1.25 & 2 & 0.010 & 0.016 & 0.974 & 0 & 0 & 0 & 10 \\
\hline $\mathrm{R} 2$ & 1.25 & 2 & 0.010 & 0.016 & 0 & 0 & 0.974 & 0 & 10 \\
\hline R3 & 1.25 & 2 & 0.025 & 0.040 & 0.935 & 0 & 0 & 0 & 10 \\
\hline R4 & 1.25 & 2 & 0.025 & 0.040 & 0 & 0 & 0.935 & 0 & 10 \\
\hline R5 & 1.25 & 2 & 0.050 & 0.080 & 0.870 & 0 & 0 & 0 & 10 \\
\hline R6 & 1.25 & 2 & 0.050 & 0.080 & 0 & 0 & 0.870 & 0 & 10 \\
\hline R7 & 1.5 & 0.5 & 0.043 & 0.057 & 0 & 0.900 & 0 & 0 & 25 \\
\hline R8 & 1.5 & 0.5 & 0.043 & 0.057 & 0 & 0 & 0.900 & 0 & 17 \\
\hline R9 & 1.5 & 0.5 & 0.043 & 0.057 & 0 & 0.495 & 0 & 0.405 & 23 \\
\hline
\end{tabular}

${ }^{a}$ Conditions: $790<T_{\text {in }}<1225 \mathrm{~K}$ and $P=1.1$ atm when $\tau=0.5 \mathrm{~s}$ (Napoli) and $P=1.05 \mathrm{~atm}$ when $\tau=2 \mathrm{~s}$ (Nancy).

resistances rolled up around their walls. The external wall reactor temperature is monitored by means of a K-type thermocouple.

In both experimental facilities, the preheating system allows for inlet temperatures $\left(T_{\text {in }}\right)$ to reach up to $1250 \mathrm{~K} . T_{\text {in }}$ is continuously monitored by a K-type shielded thermocouple located in the center of the nozzles, with a precision of $\pm 2 \mathrm{~K}$. Electronic control of the heating system gives uniform temperatures within $\pm 5 \mathrm{~K}$ over the external vessel surface and constant in time to within $\pm 0.5 \mathrm{~K}$. This allows for the maintenance of the reactor external wall at the same temperature as the inlet temperature.

The residence time of the fuel mixture in the preheating system is more than 100 times lower than the mean residence time in the reactor. Thus, oxidation of the fuel inside the injector is prevented. When a temperature increase is detected by the $T_{\text {in }}$ thermocouple, indicating the onset of ignition/oxidation reactions during the mixing process, the experimental conditions are not considered. For diluted methane mixtures, this condition does not occur in the investigated temperature range.

Gases are stored in cylinders and supplied to the system by means of calibrated digital thermal mass flow controllers supplied by BronkHorst High-Tech. They are preceded by filters to retain particulate impurities. The precision of the mass flow rates corresponds to $\pm 0.5 \%$ of set operating conditions.

Gases are provided with high purities: $99.999 \%$ for nitrogen, oxygen, and helium and $99.5 \%$ for carbon dioxide and methane.

The experiments carried out with steam-diluted mixtures rely on a water feeding system consisting of a stainless-steel cylinder, pressurized with dry nitrogen, a calibrated liquid mass flow meter, and a controlled evaporator mixer (CEM) provided by BronkHorst High-Tech. The CEM consists of a control valve, a mixing device, and a heat exchanger whose temperature is controlled by an integrated system controller. A carrier gas (nitrogen) is used to promote the evaporation process and to transport the vapor. The temperature of gas lines downstream of the evaporator is controlled by electrical coils to prevent water condensation.

The reactor pressure is continuously monitored by means of a transducer connected to the outlet from the vessels. It is kept constant in both of the apparatuses by means of a needle valve located on the gas exhaust line.

Experimental Procedures and Measurement Methodology. In each test, the total mixture mass flow rate was set for the specified residence time $\tau$, adjusted for the inlet temperature $T_{\text {in }}$ and the reactor pressure $P$. The mixture residence time is defined as $\tau=$ reactor volume/volume flow rate. For the Napoli tests, $P$ was maintained at $1.1 \mathrm{~atm}$ and $\tau$ was fixed at $0.5 \mathrm{~s}$, whereas for the Nancy tests, $P=1.05$ atm and $\tau=2 \mathrm{~s}$.

For each test, vessels were flushed with inert gas before use. After fuel injection, a period of $5 \mathrm{~min}$ was allowed to reach thermal equilibrium. Initial test conditions refer to the parameters set prior to reactions taking place. Therefore, the inlet temperature has not been varied continuously, but each experimental point corresponds to a different test.

To accurately monitor the temperature changes during the oxidation process, homemade R-type unshielded thermocouples gas welded from a very fine $\mathrm{Pt}-\mathrm{Pt} 13 \% \mathrm{Rh}$ wire $(0.2 \mathrm{~mm}$ bead size $)$ interfaced to a personal computer (PC) with a high-speed multichannel module, supplied by National Instruments, were used. A photo of the thermocouple located inside the reactor is reported in the Supporting Information. The global thermocouple response time is about $30 \mathrm{~ms}$, thus allowing for a faithful record of the reactor temperature during oscillatory behaviors with a precision of $\pm 2 \mathrm{~K}$. A thin-wall alumina double-core tube covers thermocouple wires to prevent catalytic reactions. Herein, it has to be pointed out that thermocouples made using the same procedure were used in both the JSFRs.

The outlet concentration of the reactants was analyzed by gas chromatography. In the Napoli reactor, the exit gases were cooled by 
means of a heat exchanger installed at the reactor outlet to quench the oxidation reactions. Then, gases passed through a silica gel trap to eliminate the moisture content before gas analyses. Therefore, results are reported on a dry basis. The outlet was connected to a gas chromatograph (Agilent 3000) equipped with a column MolSieve 5A and a pre-column PLOT $\mathrm{U}$ and a thermal conductivity detector (TCD).

In Nancy, the quantification of the products from the reactor was realized with the aid of two gas chromatographs (GCs). The first GC equipped with a TCD was used to quantify $\mathrm{O}_{2}$. The second GC equipped with a flame ionization detector preceded by a methanizer and a PLOT Q capillary column was used to quantify $\mathrm{CH}_{4}, \mathrm{CO}, \mathrm{CO}_{2}$, $\mathrm{C}_{2} \mathrm{H}_{4}, \mathrm{C}_{2} \mathrm{H}_{6}$, and $\mathrm{C}_{2} \mathrm{H}_{2}$.

Maximum relative errors in mole fractions are estimated to be $\pm 10 \%$ when the concentrations approach the detection threshold (about $10 \mathrm{ppm}$ ). The instrument calibration was performed daily using standard gas mixtures stored in cylinders.

Experiments were performed at least twice under all test conditions to ensure measurement reproducibility. The test repeatability was excellent under all conditions, with differences among the various tests well within the reported experimental uncertainties.

Computational Approach. Simulations were carried out using the OpenSMOKE $++^{33}$ perfectly stirred reactor (PSR) code, calculating the transient solutions of an open WSR. ${ }^{33}$ Geometrical characteristics were the same as those of the experimental reactors, i.e., a volume of $113 \mathrm{~cm}^{3}$ and an internal surface of $113 \mathrm{~cm}^{2}$ for the Napoli reactor and a volume of $85 \mathrm{~cm}^{3}$ and an internal surface of 93 $\mathrm{cm}^{2}$ for the Nancy reactor. Experimental mixture inlet conditions reported in Table 1 are declared in the input files. Because the two experimental systems are non-adiabatic, Newtonian-type heat losses were enabled. The reactor overall heat transfer coefficient $(U)$ in the JSFRs was calculated by means of an empirical correlation available in the literature ${ }^{34}$ and fixed at $1.3 \times 10^{-3} \mathrm{cal} \mathrm{cm}^{-2} \mathrm{~s}^{-1} \mathrm{~K}^{-1}$. Reactor walls were assumed to be infinitely thin with negligible temperature gradients. The wall temperature was set equal to the inlet temperature.

A recently updated detailed gas-phase chemical kinetic mechanism "POLIMI" (C1C3LT_1412) was used. It was developed by Ranzi et $\mathrm{al}^{35}$ for the pyrolysis and combustion of a large variety of fuels. The mechanism consists of 2642 elementary reactions with 107 species. Thermodynamic properties are included in the database. A detailed analysis and validation of the reliability of this scheme is discussed elsewhere. ${ }^{35}$ This kinetic mechanism was chosen as the reference scheme because it was one of the most reliable in predicting oscillatory behaviors under MILD operating conditions for both methane $e^{2,24}$ and propane $\mathrm{e}^{36,37}$ mixtures.

\section{RESULTS}

Experiments were carried out from fuel-lean to fuel-rich mixtures for a wide range of inlet temperatures, at atmospheric pressure. The bath gas was changed along with the fuel mole fraction and the overall molar fraction of diluent species (hereafter indicated as dilution "d"). The experimental conditions are summarized in Table 1. Data for cases S1, S2, and S3 are from Bagheri et al. $^{28}$ Furthermore, the data collected for each data set are provided in the Supporting Information.

To classify the combustion regimes as a function of $T_{\text {in }}$, as an exemplifying case, the reactor temperature $(T)$ and the $\mathrm{CH}_{4}$ and $\mathrm{O}_{2}$ concentrations for a stoichiometric $\mathrm{CH}_{4} / \mathrm{O}_{2}$ mixture diluted in $\mathrm{N}_{2}$ at $90 \%$ (Napoli test case $\mathrm{S} 1$ ) are reported in Figure 1.

In this figure, vertical lines identify the transition conditions from one state to another in response to a stepwise change of $T_{\text {in }}$. At low temperatures $(T<1000 \mathrm{~K})$, non-reactive conditions (I), characterized by zero temperature increase and zero fuel conversion, are identified. To increase $T_{\text {in }}$ a
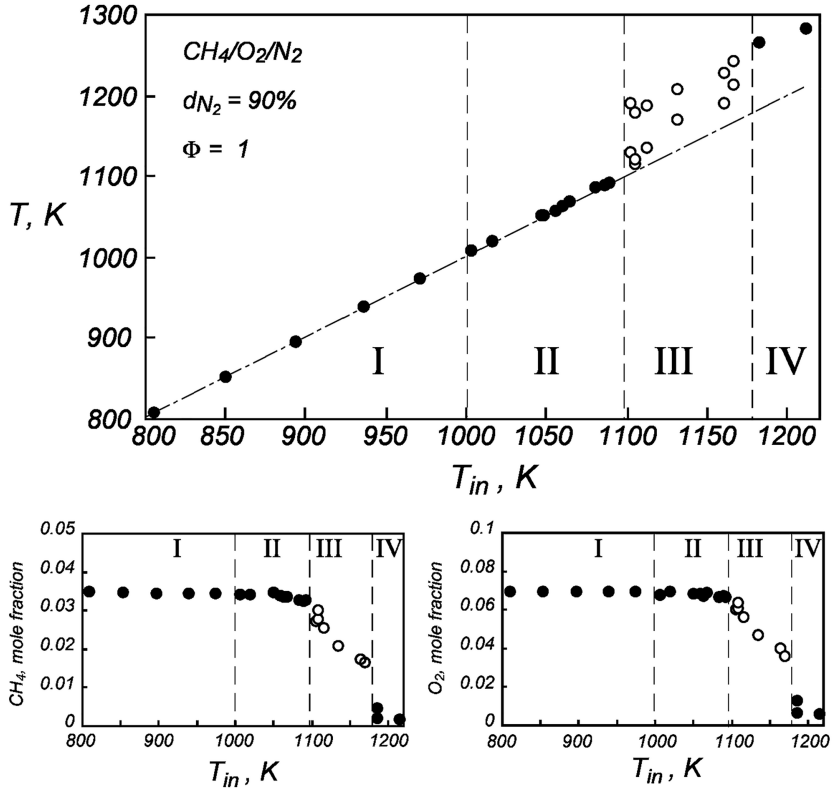

Figure 1. Experimental reactor temperature $(T)$ and reactant concentrations versus $T_{\mathrm{in}}$. Conditions: $\Phi=1, \tau=0.5 \mathrm{~s}, P=1.1$ atm, $\mathrm{N}_{2}$ bath gas, and $X_{\mathrm{CH}_{4}}=0.033$. Closed symbols represent steady states, and open symbols represent oscillatory regimes. See the text for a description of I, II, III, and IV zones.

secondary stationary state (II) with very small extents of oxidation is recognized for $1000<T_{\text {in }}<1100 \mathrm{~K}$ with a maximum temperature increase of about $5 \mathrm{~K}$. An oscillatory region (III) establishes in the $T_{\text {in }}$ range of $1100-1170 \mathrm{~K}$ with periodic temperature variations. For this oxidation regime, two $T$ values are reported for the same $T_{\text {in }}$ in Figure 1 corresponding to the maximum and minimum values of temperature $T$ detected within the oscillation cycle. In this case, the measured concentration values are averaged over time because of the time elapsed for the gas sampling before the chemical analyses; thus, only one concentration value is reported in Figure 1. To better identify these conditions, the closed symbols are substituted with open symbols.

For $T_{\text {in }}>1170 \mathrm{~K}$, the mixtures ignite and the system reaches a stationary state (IV) with the temperature increase between 70 and $80 \mathrm{~K}$ and almost complete conversion. This steady-state regime can be attained either monotonically or via damped oscillations.

The experimental condition reported in Figure 1 is used as a reference case because it includes all of the observed critical phenomena. However, the stationary state (IV) has been observed only for relatively short residence times (namely, in the Napoli reactor). This can be explained considering the relative importance of sensible heat removal by system losses at the vessel walls and the heat convective transport associated with the outflow by calculating the ratio between two characteristic times, the mixture mean residence time $\tau$, and the Newtonian cooling time $\left(t_{c}\right)$. The latter depends upon the vessel characteristic dimensions $V / S$ ( $V$ and $S$ are the vessel volume and surface, respectively) and the ratio $\rho c_{\mathrm{p}} / U$ ( $\rho$ and $c_{\mathrm{p}}$ represent the mixture density and specific heat capacity, respectively), which does not vary significantly with the temperature. When an exothermic reaction is in progress, if $\tau$ $>t_{\mathcal{c}}$, heat losses to the walls predominate over heat transport in the outflow. Therefore, the longer the residence times, the 
lower the system temperature. For both reactors, $t_{c}$ can be assumed to be equal to $0.07 \pm 0.01 \mathrm{~s}$. Considering the residence times used in the two JSFRs, $\tau / t_{\mathrm{c}}$ is about 7 for the Napoli reactor and 30 for the Nancy reactor.

Thus, both systems are far from the adiabatic condition. In particular, in the Nancy configuration, temperature increases as a result of oxidation reactions are not measurable at stationary states because the system approaches the isothermal condition. However, interestingly, temperature oscillations were still observed.

The analysis of the complex waveform periodic events could elucidate the role of parameters in triggering oscillations, and hence, it could provide some useful hints for the study of oscillatory phenomena in practical systems.

On the basis of the above classifications, $T_{\text {in }}-\Phi$ maps were constructed (Figures 2 and 3 ) considering all experimental

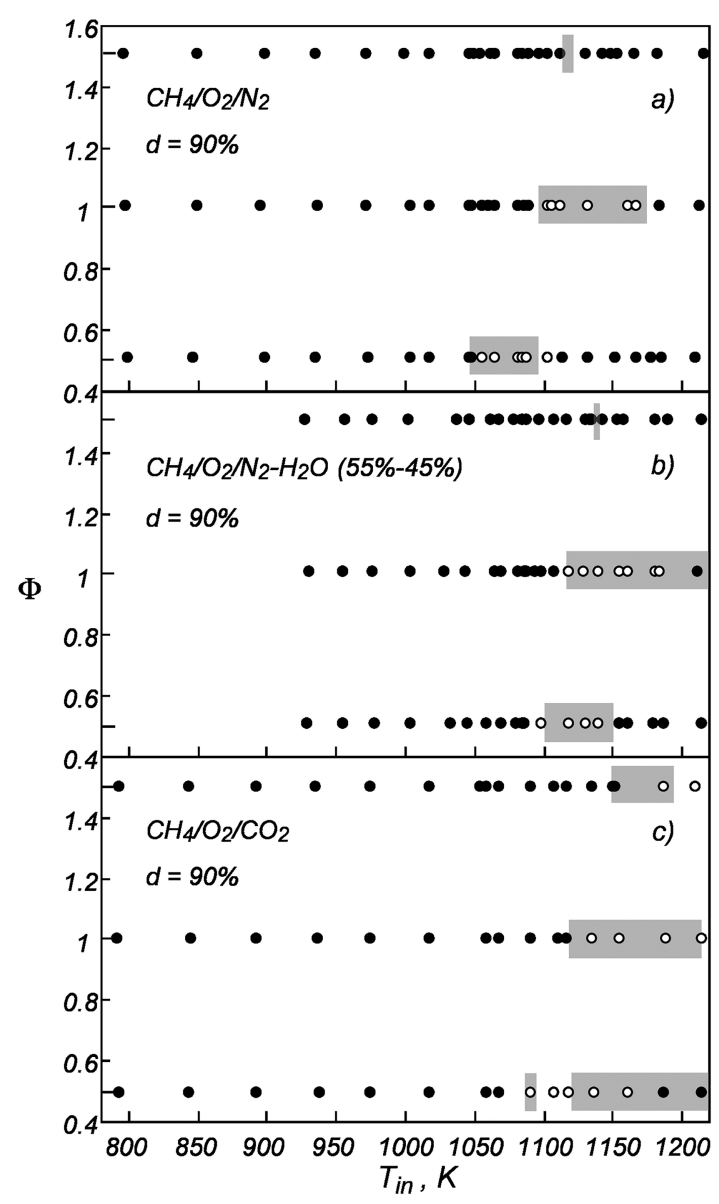

Figure 2. Experimental (symbols) and simulated (rectangles) $T_{\text {in }}-\Phi$ maps. Conditions: $\tau=0.5 \mathrm{~s}, P=1.1 \mathrm{~atm}$, and $X_{\text {bath gas }}=0.9$. (a) $\mathrm{N}_{2}$ bath gas, (b) $\mathrm{N}_{2}-\mathrm{H}_{2} \mathrm{O}$ bath gas, and (c) $\mathrm{CO}_{2}$ bath gas. Closed circles, "no oscillation"; open circles, "oscillation"; and gray rectangles, numerical oscillatory conditions simulated with the "POLIMI" model.

conditions investigated in both reactors (see Table 1). In particular, each point on a map corresponds to an experimental condition. Given that the present work is mainly concerned with oscillatory states, the demarcation of the different reaction modes is only provided on the maps for oscillatory and nonoscillatory regimes. Therefore, regimes I, II, and IV are all identified as "no oscillation" regimes with full circles, whereas dynamic conditions are represented by open circles. Maps are also provided with numerical results, where the temperature ranges of oscillating conditions are indicated by gray rectangles.

Figure 2a summarizes the Napoli experimental tests carried out for mixtures of $\mathrm{CH}_{4} / \mathrm{O}_{2}$ diluted in $\mathrm{N}_{2}$ at $90 \%$ for several equivalence ratios $(\Phi=0.5,1$, and 1.5). For $\Phi=0.5$ (L1), temperature oscillations occur for $T_{\text {in }}$ between 1055 and 1100 $\mathrm{K}$. For $\Phi=1(\mathrm{~S} 1)$, the dynamic behavior starts at $T_{\text {in }}>1100 \mathrm{~K}$ and ends at $T_{\text {in }}=1180 \mathrm{~K}$. Finally, for the fuel-rich condition (R7), the dynamic behavior was not observed in the whole investigated $T_{\text {in }}$ range.

An analogous identification of regimes can also be made when $\mathrm{H}_{2} \mathrm{O}$ or $\mathrm{CO}_{2}$ are used as diluent species.

Figure $2 \mathrm{~b}$ shows experimental results for a mixture of $\mathrm{CH}_{4} /$ $\mathrm{O}_{2}$ diluted in $\mathrm{N}_{2}$ and $\mathrm{H}_{2} \mathrm{O}$ with a relative concentration of 55 and $45 \%$ and a global mixture dilution level of $90 \%$ (L3, S3, and R9). It can be seen that steam leads to a shift of the oscillation regions toward higher $T_{\text {in }}$ with respect to the $\mathrm{N}_{2}$ diluted system. This shift is even more evident when mixtures are diluted in $\mathrm{CO}_{2}$ (L2, S2, and R8; Figure 2c). In this case, temperature oscillations also appeared for the fuel-rich condition.

Figure 3 shows the $T_{\text {in }}-\Phi$ maps for the systems diluted in $\mathrm{He}$ (panels a, c, and e) and $\mathrm{CO}_{2}$ (panels b, d, and f). Tests were repeated for three specific methane mole fractions, i.e., $X_{\mathrm{CH}_{4}}=0.01$ (a and b), 0.025 (c and d), and 0.05 (e and f), at $\tau$ $=2 \mathrm{~s}$ and for three $\Phi$ values $(0.75,1$, and 1.25$)$ with $T_{\text {in }}$ stepwise of $25 \mathrm{~K}$ (Nancy tests). Figure 3a identifies oscillatory regimes in the $T_{\text {in }}-\Phi$ plane for $X_{\mathrm{CH}_{4}}=0.01$ and $\mathrm{He}$ bath gas. The "oscillation" region covers quite a narrow temperature range of $50 \mathrm{~K}\left(1075<T_{\text {in }}<1125 \mathrm{~K}\right)$ for the fuel-lean condition (L4). Oscillations for stoichiometric mixtures (S4) involve a wider range of $T_{\text {in }}\left(T_{\text {in }}>1100 \mathrm{~K}\right)$. For the fuel-rich conditions (R1), temperature oscillatory behaviors were not detected in the whole temperature range considered.

As the methane mole fraction increases (panels $c$ and e of Figure 3), the oscillatory region on the map widens under stoichiometric conditions (S6 and S8) and shrinks for lean conditions. In particular, at $\Phi=0.75$, this region covers a temperature range from 1100 to $1125 \mathrm{~K}$ when $X_{\mathrm{CH}_{4}}=0.05$ (L8) and vanishes when $X_{\mathrm{CH}_{4}}=0.025$ (L6). Oscillations were never observed under rich conditions for mixtures diluted in He.

A similar identification of regimes can also be made when $\mathrm{CO}_{2}$ is used as bath gas (panels $b, d$, and $\mathrm{f}$ of Figure 3). Oscillatory regions are clearly wider than in the He-diluted cases. More specifically, in agreement with the data obtained at a lower residence time in the Napoli reactor, the oscillatory region extends up to fuel-rich conditions, indicating that the nature of temperature oscillations with $\mathrm{CO}_{2}$ bath gas under fuel-rich conditions is more complex, in agreement with the observations of Sabia et al. ${ }^{26}$

The performance of the chosen detailed kinetic scheme to predict experimental data was tested by means of systematic runs. As seen from the location of the gray rectangles on the maps (Figures 2 and 3), the adopted kinetic model is able to reproduce the experimental $T_{\text {in }}-\Phi$ with relatively minor differences on the location of boundaries between regions of different behaviors. Accuracy checks of the numerical procedures ensured that the predicted oscillations are not due to numerical integration problems. For validation, the 


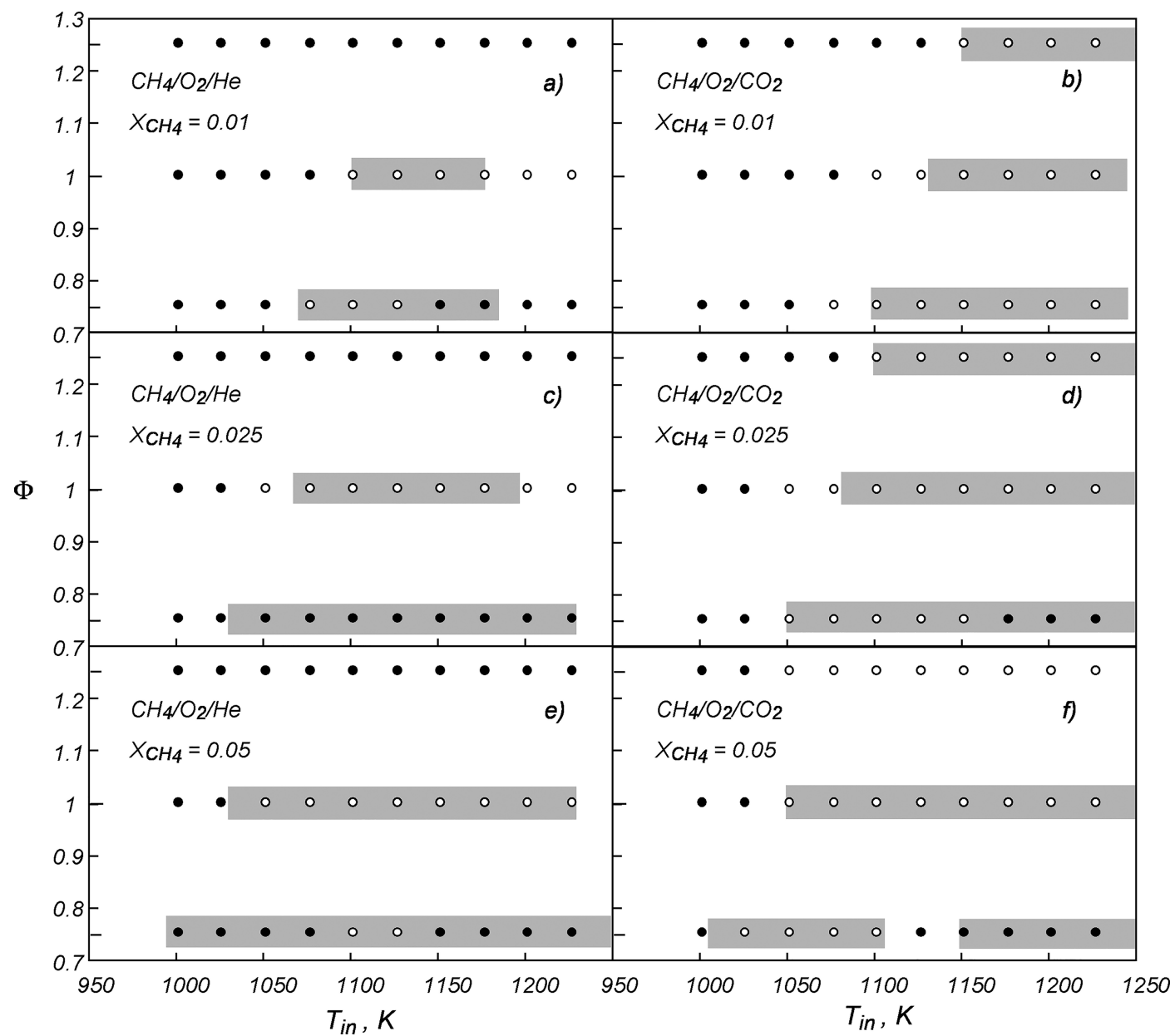

Figure 3. Experimental (symbols) and simulated (rectangles) $T_{\text {in }}-\Phi$ maps. Conditions: $\tau=2 \mathrm{~s}$ and $P=1.05$ atm. (a) He bath gas and $X_{\mathrm{CH}_{4}}=0.01$, (b) $\mathrm{CO}_{2}$ bath gas and $X_{\mathrm{CH}_{4}}=0.01$, (c) He bath gas and $X_{\mathrm{CH}_{4}}=0.025$, (d) $\mathrm{CO}_{2}$ bath gas and $X_{\mathrm{CH}_{4}}=0.025$, (e) He bath gas and $X_{\mathrm{CH}_{4}}=0.05$, and (f) $\mathrm{CO}_{2}$ bath gas and $X_{\mathrm{CH}_{4}}=0.05$. Closed circles, "no oscillation"; open circles, "oscillation"; and gray rectangles, numerical oscillatory conditions simulated with the "POLIMI" model.

simulations were also performed using Chemkin-Pro, ${ }^{38}$ yielding the same results.

In particular, the detailed kinetic scheme is able to reproduce quite accurately the influence of the equivalence ratio and the bath gas on the oscillation region boundaries. Moreover, the kinetic model correctly predicts the absence of oscillations for fuel-rich conditions when using $\mathrm{N}_{2}, \mathrm{He}$, or $\mathrm{H}_{2} \mathrm{O}$ as bath gases. It has to be pointed out that, in the case of Napoli experiments, the kinetic model predicts the occurrence of oscillations under fuel-rich conditions when $\mathrm{N}_{2}$ and $\mathrm{N}_{2}-\mathrm{H}_{2} \mathrm{O}$ are used as bath gases, but the $T_{\text {in }}$ range is very narrow (less than $5 \mathrm{~K}$ ). However, disagreements exist in model predictions for several conditions. In particular, in Figures $2 \mathrm{c}$ and $3 \mathrm{f}$, it is possible to observe that the POLIMI model predicts a discontinuity in the oscillation $T_{\text {in }}$ range under fuel-lean conditions. Such a behavior was not experimentally observed. Furthermore, in panels $\mathrm{d}$ and e of Figure 3, for fuel-lean conditions, the numerically predicted $T_{\text {in }}$ range for temperature oscillations is wider compared to the experimental $T_{\text {in }}$ range, and in Figure $3 \mathrm{c}$, the model predicts oscillations under fuel-lean conditions that were not experimentally detected. In addition, in Figure 3f, oscillations are not predicted under rich conditions, whereas they were detected experimentally.
To show some characteristic features of temperature oscillations as a function of $T_{\text {in }}$, four typical temporal temperature profiles are displayed in Figures 4 and 5 .

Figure 4 refers to stoichiometric $\mathrm{CH}_{4} / \mathrm{O}_{2}$ diluted in $\mathrm{N}_{2}$ at $90 \%$ (S1) preheated to $T_{\text {in }}=1100 \mathrm{~K}$ (Figure $4 \mathrm{a}$ ) and $T_{\text {in }}=$ $1165 \mathrm{~K}$ (Figure 4b). The periodic profiles are reported after ignition; thus, the initial value is arbitrary. In Figure $4 \mathrm{a}$, the temperature increases slowly at first then abruptly up to a maximum value, followed by an instantaneous temperature decrease. The oscillation period is about $6.7 \mathrm{~s}$ with an amplitude of about $60 \mathrm{~K}$. The minimum temperature is about $25 \mathrm{~K}$ higher than $T_{\text {in }}$. As $T_{\text {in }}$ is increased (Figure $4 \mathrm{~b}$ ), the temporal temperature profile has a different shape with a lower period (less than $1 \mathrm{~s}$ ).

These two profiles delineate a characteristic feature of the oscillatory behaviors: to increase $T_{\mathrm{in}}$, temporal profiles become more symmetric, while the oscillation amplitude decreases and the frequency increases. Furthermore, the difference between the minimum temperature and the inlet temperature also increases. These observations rule out the possibility of classifying the identified periodic phenomenon as multiple ignitions. The periodicity should be a feature of the kinetic mechanism itself and is not an artifact of flow operation. 

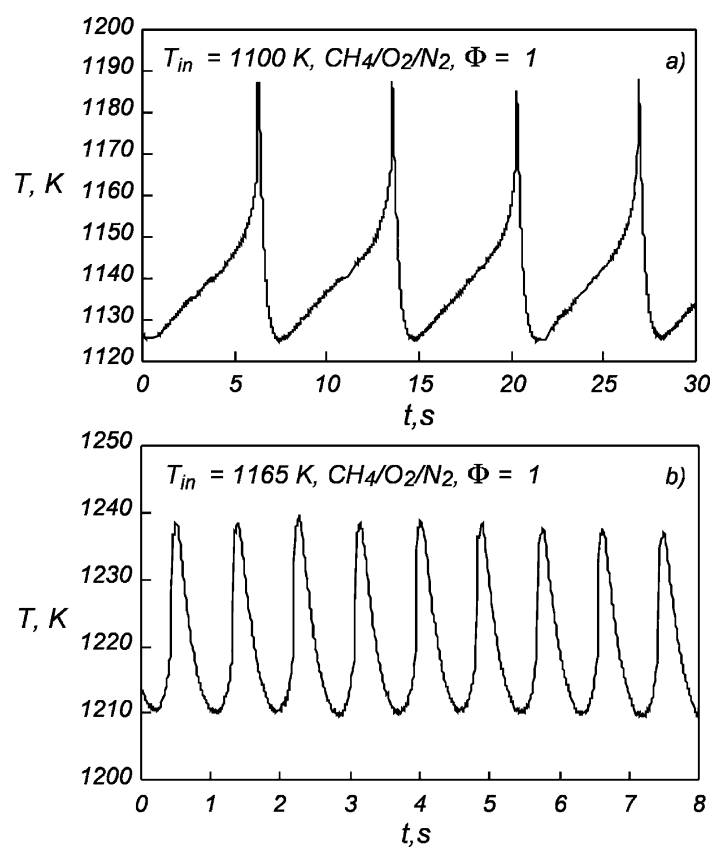

Figure 4. Representative experimental temporal temperature profiles obtained at $\Phi=1$ in $\mathrm{N}_{2}$ bath gas with $X_{\mathrm{CH}_{4}}=0.033$ and $\tau=0.5 \mathrm{~s}$ at (a) $T_{\text {in }}=1100 \mathrm{~K}$ and (b) $T_{\text {in }}=1165 \mathrm{~K}$. The initial time is arbitrary.
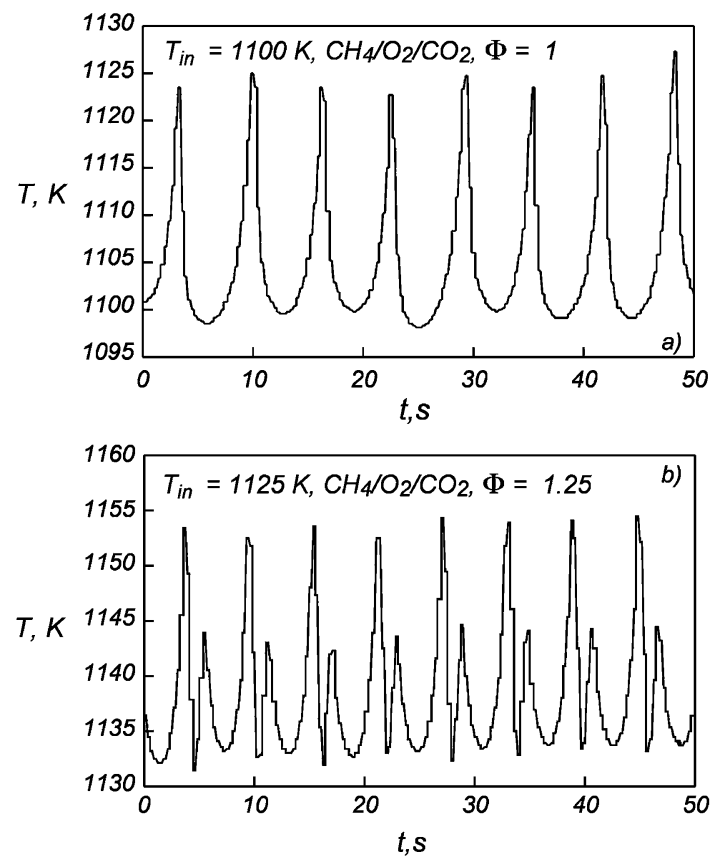

Figure 5. Representative experimental temporal temperature profiles obtained in $\mathrm{CO}_{2}$ bath gas with $X_{\mathrm{CH}_{4}}=0.025$ and $\tau=2 \mathrm{~s}$ at (a) $\Phi=1$ and $T_{\text {in }}=1100 \mathrm{~K}$ and $(\mathrm{b}) \Phi=1.25$ and $T_{\text {in }}=1125 \mathrm{~K}$. The initial time is arbitrary.

Figure 5 refers to $\mathrm{CH}_{4} / \mathrm{O}_{2}$ mixtures diluted in $\mathrm{CO}_{2}$, obtained at $\tau=2 \mathrm{~s}$. In particular, Figure $5 \mathrm{a}$ is for a stoichiometric mixture preheated to $T_{\text {in }}=1100 \mathrm{~K}(\mathrm{~S} 7)$, while Figure $5 \mathrm{~b}$ refers to a fuel-rich mixture $(\Phi=1.25)$ preheated to $T_{\text {in }}=1125 \mathrm{~K}$ (R4).

In Figure 5a, the temporal profile is symmetric and the oscillation period is about $6 \mathrm{~s}$, with an amplitude of about 25 $\mathrm{K}$. The minimum temperature is equal to the inlet temperature.
As the equivalence ratio is increased (Figure $5 \mathrm{~b}$ ), the temporal temperature profile has the same period but a different shape. In particular, two maxima can be identified within each oscillation cycle, with higher amplitude for the first peak. This confirms that the nature of temperature oscillations with $\mathrm{CO}_{2}$ under fuel-rich conditions is more complex, in agreement with Sabia et al. ${ }^{26}$ Other examples of temporal temperature profiles are provided in the Supporting Information.

The computed temporal temperature profiles are not reported in Figures 4 and 5 because, although the overall features of the computed temperature history resemble the experimental measurements very closely, the predicted temperature increase is substantially larger than the experimental (usually within $200 \mathrm{~K}$ ). This occurs because the predicted temperature oscillations are characterized by spike variations in less than $10 \mathrm{~ms}$, and even though the response time of the thermocouples is very short $(\cong 30 \mathrm{~ms})$, the temperature increase cannot be properly resolved in time. A detailed analysis of numerical temperature profiles can be found in the study by Bagheri et al. ${ }^{28}$

Figure 6 shows the experimental (symbols) and numerical (lines) oscillation frequencies as a function of $T_{\mathrm{in}}$, in two
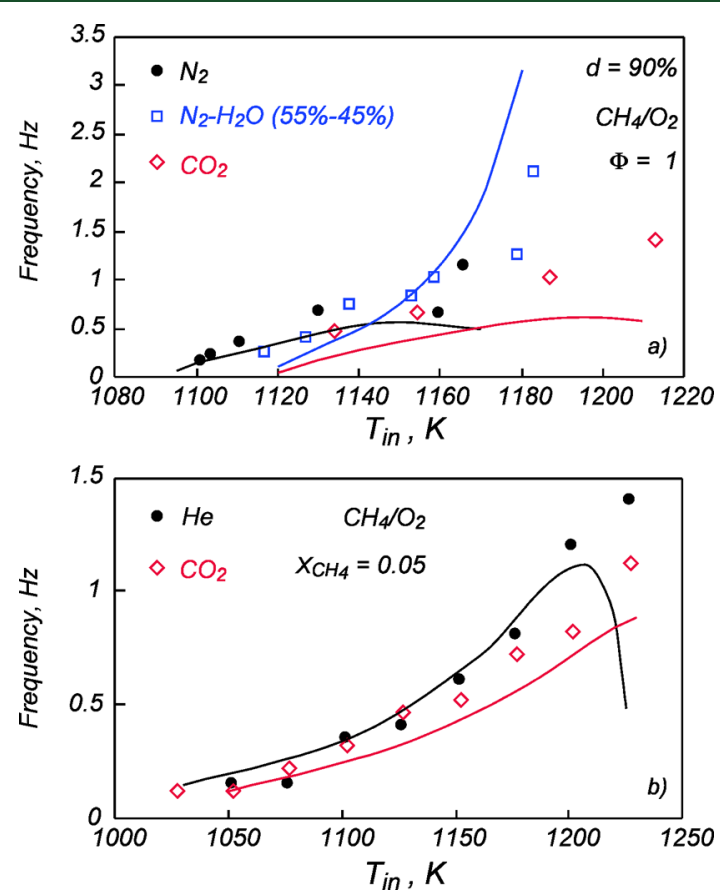

Figure 6. Experimental (symbols) and numerical (lines) oscillation frequency as a function of $T_{\text {in }}$ at $\Phi=1$ in different bath gases with (a) $X_{\mathrm{CH}_{4}}=0.033$ and $\tau=0.5 \mathrm{~s}$ and (b) $X_{\mathrm{CH}_{4}}=0.05$ and $\tau=2 \mathrm{~s}$.

representative sets of experiments. In particular, Figure $6 \mathrm{a}$ refers to stoichiometric mixtures diluted in $\mathrm{N}_{2}, \mathrm{~N}_{2}-\mathrm{H}_{2} \mathrm{O}$, and $\mathrm{CO}_{2}$, with $X_{\mathrm{CH}_{4}}=0.033$ and $\tau=0.5 \mathrm{~s}(\mathrm{~S} 1, \mathrm{~S} 2$, and S3), whereas Figure $6 \mathrm{~b}$ is related to stoichiometric mixtures diluted in $\mathrm{He}$ and $\mathrm{CO}_{2}$, with $\mathrm{X}_{\mathrm{CH}_{4}}=0.05$ and $\tau=2 \mathrm{~s}$ (S8 and S9).

For all bath gases, frequencies are relatively low at first. As $T_{\text {in }}$ increases, oscillation frequencies increase. In both figures (panels a and $\mathrm{b}$ of Figure 6), $\mathrm{CO}_{2}$ leads to a lower frequency with respect to other bath gases. The data related to $\mathrm{N}_{2}-\mathrm{H}_{2} \mathrm{O}$ dilution (Figure 6a) lie between those obtained using $\mathrm{N}_{2}$ bath gas and those related to $\mathrm{CO}_{2}$ bath gas for $T_{\text {in }}<1140 \mathrm{~K}$. For $T_{\text {in }}$ $>1140 \mathrm{~K}$, this trend is reversed and the $\mathrm{N}_{2}-\mathrm{H}_{2} \mathrm{O}$-diluted 
system displays higher frequencies than the other two mixtures. Overall, Figure 6 suggests that the oscillation frequencies are significantly modified by the presence of different bath gases and are strongly dependent upon $T_{\text {in }}$.

The POLIMI kinetic model satisfactorily predicts the experimental trends. However, dependent upon the parameters, a significantly longer period is predicted by the kinetic model at the highest $T_{\text {in }}$ compared to experimental results, with a maximum deviation of $1.33 \mathrm{~s}$.

\section{DISCUSSION}

The factors that govern the stability of stationary states and the establishment of temperature oscillations need to be understood using numerical analysis. The reference model gives a satisfactory, qualitative, and quantitative account for the $\Phi-T_{\text {in }}$ regimes along with oscillatory frequencies as $T_{\text {in }}$ and mixture composition are changed. Therefore, numerical analyses of complex dynamic behavior can be used to understand the role of elementary reactions in determining the observed behaviors.

It is well-known that a central feature of oscillatory regimes is a negative feedback mechanism (i.e., the reaction products influence the rates of earlier reaction steps in the mechanism) that restricts the runaway acceleration of an intermediate concentration and differentiates the oscillatory reaction from an explosion, ${ }^{4}$ where the feedback is always positive. Negative feedback can be caused by a number of different phenomena, some purely physical and others of chemical nature. ${ }^{4}$ As reported in the Introduction, oscillatory regimes may be significantly influenced by heat losses. Therefore, as a first step, it is appropriate to analyze the influence of the heat loss on the observed phenomenon (Figure 7 ).

Figure $7 \mathrm{a}$ shows the effect of modifications to the heat transfer coefficient $(U)$ on the steady-state reaction temperatures as a function of $T_{\text {in }}$ for a stoichiometric $\mathrm{CH}_{4} / \mathrm{O}_{2} / \mathrm{N}_{2}$ mixture. The different conditions analyzed allow for sensible variation of the system working temperature, thus representing an indirect way to parametrically evaluate the operating conditions that boost the onset of oscillatory behavior. In addition, the system was modeled under the asymptotic assumptions of adiabatic (Figure $7 \mathrm{~b}$ ) and isothermal (Figure $7 \mathrm{c}$ ) conditions to highlight crucial aspects of the problem.

Figure $7 \mathrm{a}$ shows the reactor temperature for a stoichiometric mixture diluted in $\mathrm{N}_{2}$ at $90 \%$ by varying the heat transfer coefficient $(U)$ from 0.0013 to $0.13 \mathrm{cal} \mathrm{cm}^{-2} \mathrm{~s}^{-1} \mathrm{~K}^{-1}$ in steps of 1 order of magnitude. As expected, the temperature values are inversely proportional to the heat loss coefficients. For $U=$ $0.0013 \mathrm{cal} \mathrm{cm}^{-2} \mathrm{~s}^{-1} \mathrm{~K}^{-1}$, the system temperature remains equal to $T_{\text {in }}$ up to $T_{\text {in }}=1080 \mathrm{~K}$; then for $1080<T_{\text {in }}<1090 \mathrm{~K}$, the temperature increases very slightly; and finally, at about $T_{\text {in }}=$ $1090 \mathrm{~K}$, the mixture ignites and temperature oscillations are predicted. The ignition condition is identified on the figure by an open circle. In Figure $7 \mathrm{a}$, the shadowed area under the $T_{\max }$ curves identifies the maximum and minimum values of temperature oscillations. For these inlet conditions, the minimum reactor temperature during oscillations is equal to the inlet temperature. Oscillatory behavior is identifiable up to $T_{\text {in }}=1180 \mathrm{~K}$ (square symbol). For $T_{\text {in }}>1180 \mathrm{~K}$, the system shows a steady stationary state behavior with a temperature increase of about $80 \mathrm{~K}$, in agreement with the experimental results reported in Figure 1.

For $U=0.013 \mathrm{cal} \mathrm{cm}^{-2} \mathrm{~s}^{-1} \mathrm{~K}^{-1}$, the behavior is very similar but the mixture ignition occurs at higher $T_{\text {in }}$ (about $1120 \mathrm{~K}$ ) and then temperature oscillations are established. They have

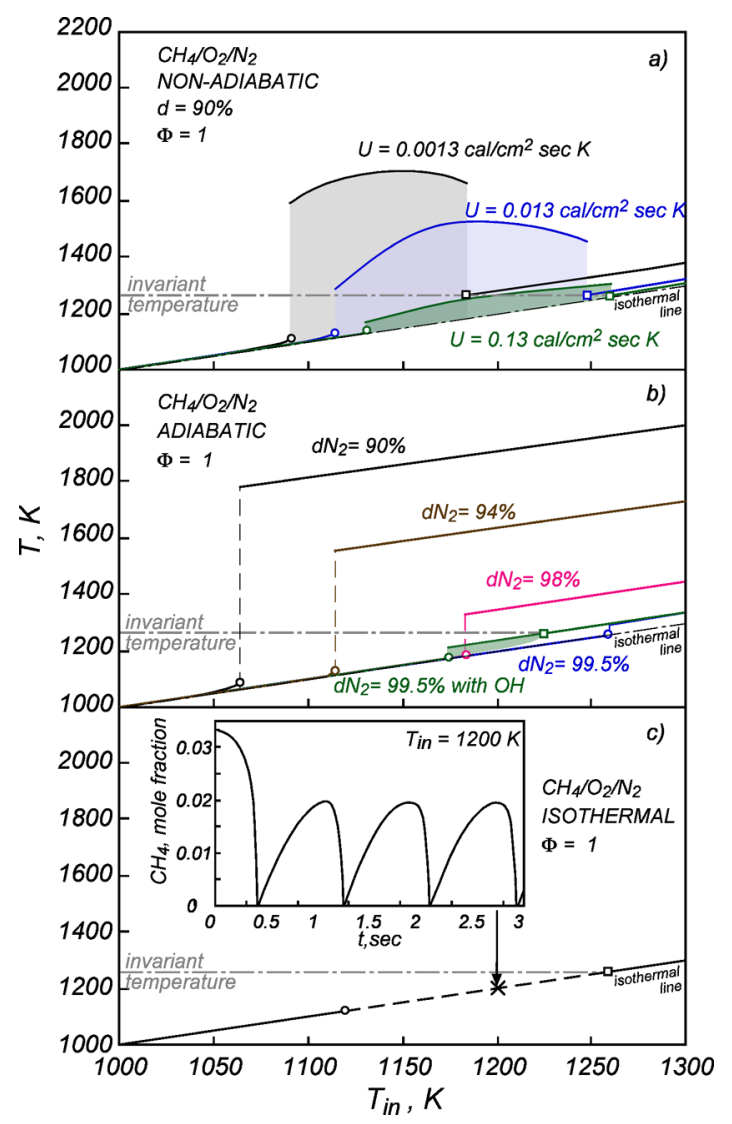

Figure 7. Computed reactor temperature $(T)$ versus inlet temperature $\left(T_{\text {in }}\right)$ under (a) non-adiabatic conditions for different values of the heat transfer coefficient, (b) adiabatic conditions for different dilutions, and (c) isothermal conditions. Conditions: $\Phi=1, \tau=0.5$ s, $P=1.1 \mathrm{~atm}$, and $\mathrm{N}_{2}$ bath gas. Open circles, ignition condition; open squares, end of oscillations; and shadowed area, maximum and minimum values of temperature oscillations.

lower amplitudes with respect to the previous case. Temperature oscillations die out at $T_{\text {in }}=1250 \mathrm{~K}$, when a steady-state condition is reached. Similar observations apply for the case of $U=0.13 \mathrm{cal} \mathrm{cm}^{-2} \mathrm{~s}^{-1} \mathrm{~K}^{-1}$. Ignition occurs for $T_{\text {in }}=1130 \mathrm{~K}$ with the onset of temperature oscillations that cease at $T_{\text {in }}=$ $1260 \mathrm{~K}$. Interestingly, these oscillations are observed when the temperature decreases below a fixed value, i.e., $T=1260 \mathrm{~K}$, reported in Figure 7 with a horizontal dot-dashed line, thus suggesting that kinetics is controlling the suppression of oscillations.

Figure $7 \mathrm{~b}$ shows the behavior of the ideal PSR under adiabatic conditions for a stoichiometric $\mathrm{CH}_{4} / \mathrm{O}_{2}$ mixture diluted in $\mathrm{N}_{2}$ at different levels (from 90 to $99.5 \%$ ).

For $\mathrm{N}_{2}=90 \%$, the ignition occurs at about $T_{\text {in }}=1060 \mathrm{~K}$ and then the system reaches a steady stationary state. No oscillatory behavior is predicted. As the dilution level of the mixture increases $\left(\mathrm{dN}_{2}=94\right.$ and $\left.98 \%\right)$, the autoignition event occurs at higher $T_{\text {in }}$ with a lower temperature increase. None of the systems exhibits a periodic dynamic behavior because of the larger temperature increase. In fact, when ignition occurs, the working temperature $T$ is above $1260 \mathrm{~K}$; thus, no oscillations are observed, in agreement with Figure $7 \mathrm{a}$. In the case of $\mathrm{dN}_{2}=99.5 \%$, the ignition occurs at $1260 \mathrm{~K}$ with a temperature increase of $35 \mathrm{~K}$. In this case, the ignition occurs when $T_{\text {in }}$ exceeds the identified threshold temperature; thus, no oscillations are observed. However, for the latter system, a 
further simulation has been considered. In particular, the autoignition event was forced by doping the inlet mixture with a low concentration of $\mathrm{OH}(200 \mathrm{ppm})$. For this case, the autoignition occurs for $T_{\text {in }}=1200 \mathrm{~K}$ and oscillations are observed. The periodic dynamic behavior can no longer be sustained when the system temperature exceeds $1260 \mathrm{~K}$ (horizontal dot-dashed line). It is worth noting that the addition of $\mathrm{OH}$ does not significantly change $(1 \mathrm{~K})$ the system temperature in the high-temperature stationary solution.

On the other hand, transition from low-temperature steady states to periodic oscillatory states is attainable when the mixture residence time is higher than the mixture ignition delay time. Because an increase of the heat transfer coefficient or $X_{\mathrm{N}_{2}}$ leads to an increase of the ignition delay time, a shift of the appearance of oscillations with $T_{\text {in }}$ is observed in panels a and $b$ of Figure 7.

In addition, it was noted that an oscillatory dynamic regime is also observed under isothermal conditions, as shown in Figure $7 \mathrm{c}$. Although the temperature is not allowed to vary in this latter case (the shadow area is replaced by a dashed line), oscillations in the methane mole fraction over time are highlighted in the inset of Figure $7 \mathrm{c}$, referring to inlet temperature conditions of $1200 \mathrm{~K}$. Interestingly, methane concentration oscillations occur when $T_{\text {in }}$ is in the temperature range of $1120-1260 \mathrm{~K}$. These simulations showed some peculiarity of the oxidation process at an intermediate temperature for stoichiometric $\mathrm{CH}_{4} / \mathrm{O}_{2}$ mixtures: The system is prone to exhibit periodic dynamic behavior when the working temperature is approximately in the range of 1120$1260 \mathrm{~K}$, even under adiabatic or isothermal conditions, and the high-temperature steady state always occurs for $T \geq 1260 \mathrm{~K}$.

Further simulations were performed for lean mixtures $(\Phi=$ 0.5 ) diluted in $\mathrm{N}_{2}$ at $90 \%$. They confirmed the presence of an invariant temperature that marks the shift from oscillatory behaviors to high-temperature steady states. This temperature differs from the temperature identified for a stoichiometric mixture, thus further highlighting the chemical nature of the oscillatory phenomenon.

As discussed in the Introduction, oscillatory cool flames in LTC conditions arise from the interaction between heat release, complex chemical kinetics, and heat losses; therefore, they could not be identified in adiabatic or isothermal conditions. Moreover, cool flame regions for higher hydrocarbons occur at lower temperatures, where peroxide species play the major role in favoring branching or termination. The results discussed in the present study indicate a rather different type of phenomenon occurring in diluted mixtures, at intermediate inlet temperatures (1050-1200 K).

As mentioned in the Introduction to this study, the oscillations observed in the oxidation of hydrogen or syngas mixtures originate from a kinetic interaction between free radical chain-branching and termination reactions (i.e., $\mathrm{H}+\mathrm{O}_{2}$ $=\mathrm{OH}+\mathrm{O}$ versus $\left.\mathrm{H}+\mathrm{O}_{2}+\mathrm{M}=\mathrm{HO}_{2}+\mathrm{M}\right)$. The last reaction is promoted by the high collisional efficiency of water formed during mixture oxidation. In particular, the POLIMI mechanism proposes a collisional efficiency for $\mathrm{H}_{2} \mathrm{O} 14$ times higher than that of nitrogen. To decouple possible relevant effects of reactions belonging to the $\mathrm{H}_{2} / \mathrm{O}_{2}$ subsystem, further simulations were performed, setting $\mathrm{H}_{2} \mathrm{O}$ and $\mathrm{CO}_{2}$ third-body efficiencies equal to the nitrogen efficiency. Interestingly, temperature oscillations were still predicted, thus suggesting that oscillations observed for methane mixtures arise from a different kinetic subset.

Rate of reaction (RR) analyses, flux diagrams, and first-order temperature sensitivity analyses were used to determine the rate-limiting reactions for different $T_{\text {in }}$, considering a stoichiometric mixture diluted at $90 \%$ in $\mathrm{N}_{2}$. The numerical analysis has been performed for simplicity under isothermal conditions.

The most significant and representative results ( $R R$ analyses) are reported in Figure 8, showing the rate of the

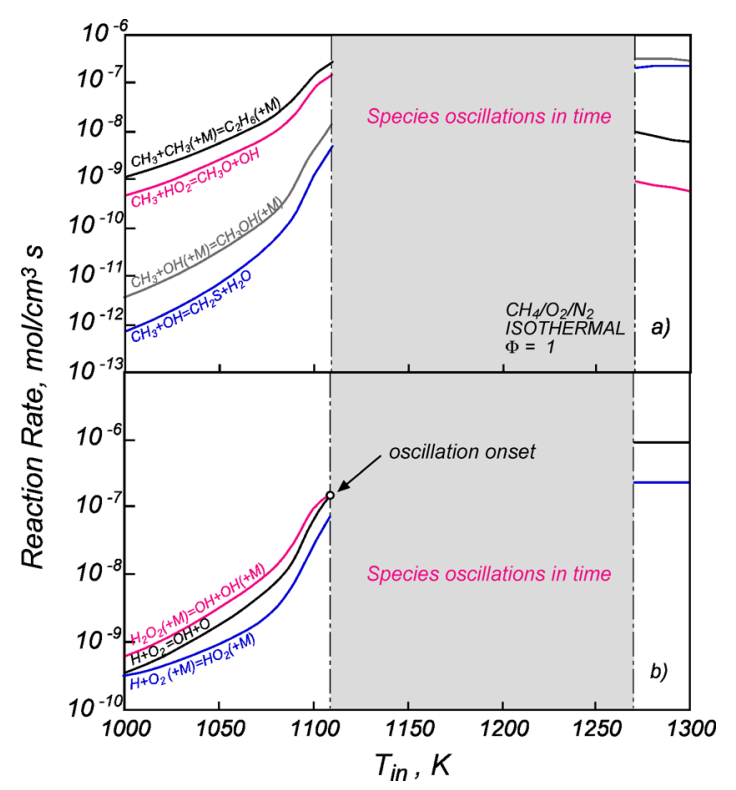

Figure 8. RR analysis for key reactions involving the (a) methyl radical and (b) $\mathrm{H}_{2} / \mathrm{O}_{2}$ subset as a function of $T_{\text {in }}$ under isothermal conditions. Conditions: $\Phi=1, \tau=0.5 \mathrm{~s}, P=1.1 \mathrm{~atm}$, and $\mathrm{N}_{2}$ bath gas. The gray area represents the $T_{\text {in }}$ range in which oscillations are predicted.

controlling reactions as a function of the inlet temperature. The aim of Figure 8 is not to show the whole kinetic routes that lead to methane conversion as a function of $T_{\text {in }}$ but to show how kinetics change from slow combustion to hightemperature conditions. In previous papers, ${ }^{2,26}$ the authors highlighted the strong competition between the methyl oxidation channels and methyl recombination to ethane, occurring at intermediate temperatures. Given this information, only the reaction rates involving methyl radicals are reported in Figure 8a.

The highlighted gray area represents the $T_{\text {in }}$ range in which oscillations are predicted. The main reaction paths change substantially moving from the region of slow reaction to the oscillatory region and from the oscillatory region to the hightemperature region.

At low temperatures $\left(1000<T_{\text {in }}<1100 \mathrm{~K}\right)$, methane is converted to methyl radicals by means of $\mathrm{H}$-abstraction reactions (mostly by $\mathrm{OH}$ and $\mathrm{HO}_{2}$ not reported in Figure 8), which is subsequently oxidized to $\mathrm{CH}_{3} \mathrm{O}$, formaldehyde, formyl radical, and $\mathrm{CO}$. Alternatively, two methyl radicals can either react to form ethane $\left(\mathrm{CH}_{3}+\mathrm{CH}_{3}+\mathrm{M}=\mathrm{C}_{2} \mathrm{H}_{6}+\mathrm{M}\right)$, terminating the radical chain, or enhance reactivity through propagation reactions, such as $\mathrm{CH}_{3}+\mathrm{HO}_{2}=\mathrm{CH}_{3} \mathrm{O}+\mathrm{OH}$. This latter reaction, in particular, despite being formally a 
propagation step, converts two relatively unreactive radicals $\left(\mathrm{CH}_{3}\right.$ and $\left.\mathrm{HO}_{2}\right)$ to very reactive radicals $\left(\mathrm{CH}_{3} \mathrm{O}\right.$ and $\left.\mathrm{OH}\right)$.

As a result of the relative stability of $\mathrm{HO}_{2}$ in the temperature window $\left(1000<T_{\text {in }}<1100 \mathrm{~K}\right)$, large amounts of $\mathrm{H}_{2} \mathrm{O}_{2}$ are formed via $\mathrm{H}$-abstraction reactions. $\mathrm{H}_{2} \mathrm{O}_{2}$ is rapidly decomposed to $\mathrm{OH}$ radicals through the third-body reaction $\mathrm{H}_{2} \mathrm{O}_{2}+$ $\mathrm{M}=\mathrm{OH}+\mathrm{OH}+\mathrm{M}$. This strongly enhances reactivity, providing radicals that produce methyl from methane.

At high temperatures $\left(T_{\text {in }}>1260 \mathrm{~K}\right)$, methyl radicals mainly react with $\mathrm{OH}$ via the reactions $\mathrm{CH}_{3}+\mathrm{OH}+\mathrm{M}=\mathrm{CH}_{3} \mathrm{OH}+$ $\mathrm{M}$ and $\mathrm{CH}_{3}+\mathrm{OH}+\mathrm{M}=\mathrm{CH}_{2}(\mathrm{~S})+\mathrm{H}_{2} \mathrm{O}$. It is worth noting that, at high temperatures, the $\mathrm{RR}$ of these reactions is 1 order of magnitude higher than the methyl recombination reaction to ethane. The radicals necessary to sustain the branching mechanism are provided by the reaction $\mathrm{H}+\mathrm{O}_{2}=\mathrm{OH}+\mathrm{O}$.

Figure $8 \mathrm{~b}$ shows how the onset of oscillations occurs at a noticeable point, i.e., when the low- and high-temperature branching reaction rates involving $\mathrm{H}$ radical and $\mathrm{O}_{2}$ become equal, better explaining the shift as a function of $T_{\text {in }}$ of the transition from low-temperature steady states to periodic oscillatory states observed in panels $\mathrm{a}$ and $\mathrm{b}$ of Figure 7. Temperatures between 1120 and $1260 \mathrm{~K}$ mark the regime shift between intermediate- and high-temperature chemistries. It has to be pointed out that, in Figure $8 \mathrm{~b}$, the curve relative to the RR of the hydroperoxide decomposition is not reported at $T_{\text {in }}>1260 \mathrm{~K}$ because it becomes negative (thus not diagrammable on the log scale) with negligible values.

For completeness, the same reaction rates are reported in Figure 9 for one oscillation cycle at $T_{\text {in }}=1200 \mathrm{~K}$, for the same

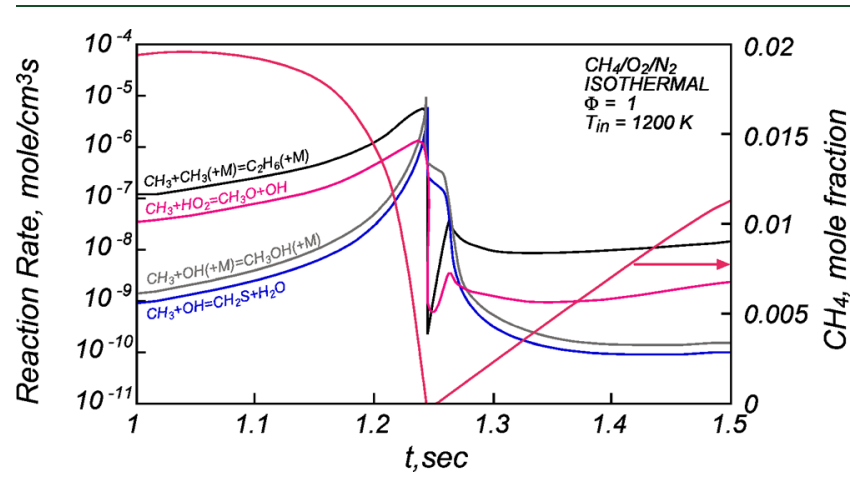

Figure 9. RR analysis for key reactions involving the methyl radical (left axis) and methane mole fraction (right axis) as a function of time for one oscillation cycle under isothermal conditions. Conditions: $\Phi=$ $1, \tau=0.5 \mathrm{~s}, P=1.1 \mathrm{~atm}, \mathrm{~N}_{2}$ bath gas, and $T_{\text {in }}=1200 \mathrm{~K}$.

reference mixture reported in Figure 7c. Such operating conditions lead to the establishment of species concentration oscillations in time. Note that the methane profile is also reported on the secondary axis.

It is possible to note that, during an oscillation period, when the methane concentration is relatively high, the methyl recombination to ethane and the oxidation to $\mathrm{CH}_{3} \mathrm{O}$ by $\mathrm{HO}_{2}$ radicals are the most important reactions. The reactions between $\mathrm{CH}_{3}$ and $\mathrm{OH}$ radicals $\left[\mathrm{CH}_{3}+\mathrm{OH}+\mathrm{M}=\mathrm{CH}_{3} \mathrm{OH}+\right.$ $\mathrm{M}$ and $\mathrm{CH}_{3}+\mathrm{OH}+\mathrm{M}=\mathrm{CH}_{2}(\mathrm{~S})+\mathrm{H}_{2} \mathrm{O}$ ] become important only when methane is fully converted as a result of the higher availability of radicals. After methane reaches its minimum value, species accumulated within the reactor mix with the incoming unburned mixture. However, the methyl recombination reaction is still predominant and subtracts $\mathrm{CH}_{3}$ radicals to the oxidation pathways, thus suppressing the conversion of methane. It accumulates in the reactor, restarting the new cycle.

In summary, the RR analyses suggest that the oscillations occur when the high-temperature branching pathway overcomes the hydrogen peroxide pathway, thus producing a large amount of radical species that can promote methane oxidation reactions. On the other hand, the recombination channel is very active and subtracts $\mathrm{CH}_{3}$ radicals to the oxidative channel, thus decreasing the system reactivity.

The dynamic behavior dies out when the reactions between methyl radicals and $\mathrm{OH}\left[\mathrm{CH}_{3}+\mathrm{OH}+\mathrm{M}=\mathrm{CH}_{3} \mathrm{OH}+\mathrm{M}\right.$ and $\mathrm{CH}_{3}+\mathrm{OH}+\mathrm{M}=\mathrm{CH}_{2}(\mathrm{~S})+\mathrm{H}_{2} \mathrm{O}$ ] are fast enough to relieve the system by the inhibiting effect of the recombination reaction.

Therefore, it is clear that diluted combustion conditions force the reactive system to work in a very narrow temperature window, where the competition between oxidation and recombination is stressed. This competition results in the peculiar behavior discussed above, which is strongly dependent upon the temperature, equivalence ratio, and bath gas composition.

As a matter of fact, ad hoc experimental measurements aiming at testing the effect of the equivalence ratio, inlet temperature, and bath gas provide direct evidence for the kinetic foundations discussed above.

In particular, the displacement of the oscillations to a higher inlet temperature at a constant equivalence ratio, when the diluent is changed from $\mathrm{He}$ or $\mathrm{N}_{2}$ to $\mathrm{H}_{2} \mathrm{O}$ or $\mathrm{CO}_{2}$, is consistent with an increase of the overall third-body efficiencies. In fact, the role of termolecular reactions is reinforced by the high collisional efficiencies of such species, postponing the shift between the $\mathrm{H}_{2}$ sub-system branching reactions $\left(\mathrm{H}_{2} \mathrm{O}_{2}+\mathrm{M}=\right.$ $\mathrm{OH}+\mathrm{OH}+\mathrm{M}$ versus $\mathrm{H}+\mathrm{O}_{2}=\mathrm{OH}+\mathrm{O}$ ), thus the onset of oscillations, to higher inlet temperatures, and reinforcing the role of methyl recombination to ethane, thus forcing the end of the oscillatory behavior at higher inlet temperatures. In the case of the non-isothermal system, it also has to be considered that such species have higher heat capacities with respect to $\mathrm{N}_{2}$ or $\mathrm{He}$; thus, in the same operating conditions, also, the reactor working temperature is lower. This can affect the relative weight of competitive reactions.

Despite the discussion presented here mostly referring to chemical kinetic aspects, none of the oscillatory phenomena can be solely attributed to isothermal kinetics. Heat release and dissipation are integral to the occurrence of such events and are of particular relevance in real devices. ${ }^{39}$ Moreover, the competition between exothermic oxidation and endothermic pyrolysis must also be taken into account.

The kinetic model used here to interpret the experimental measurements shows good agreement with boundaries on the $\Phi-T_{\text {in }}$ maps and for the oscillatory frequencies. However, some disagreements were observed. It has to be pointed out that the evaluation of the heat transfer coefficient used in the adopted model is affected by uncertainties. However, it was observed that such an uncertainty does not significantly change the predictions in the explored experimental conditions. Indeed, a similar satisfactory agreement is observed for isothermal conditions. However, under isothermal conditions, the predicted boundaries diverge toward slightly higher inlet temperatures compared to the measurements. This further confirms the predominant nature of chemical effects on the occurrence of such phenomena. 
An indirect proof of this statement is given by the fact that simulations using different kinetic mechanisms available in the literature (see the Supporting Information) lead to noteworthy disagreement among model predictions themselves. This suggests that some additional effort should be dedicated to the development of detailed kinetic schemes to correctly describe fuel oxidation processes under diluted combustion conditions, at intermediate temperature.

The general importance of recombination is particularly significant and represents a major limitation in comparing experimental and modeling results because the rate constants for such reactions can vary with the type of bath gas used. Therefore, to match modeling to experiments with any accuracy, it seems that the third-body collisional efficiencies have to be carefully evaluated. Such a consideration is often either very difficult or neglected.

For all of the above reasons, there is still much scope in developing and refining models for the simulation of the large variety of observable dynamic behaviors of methane combustion.

In this regard, the present work provides a safe guidance to reliabilities of modeling, opportunities for further research, and rational employment of efforts.

\section{CONCLUSION}

Two JSFRs were used to characterize the oscillatory behavior of $\mathrm{CH}_{4} / \mathrm{O}_{2}$ mixtures as a function of system external parameters, such as the inlet temperature, equivalence ratio, residence time, methane mole fraction, and chemical structure of the bath gas $\left(\mathrm{He}, \mathrm{N}_{2}, \mathrm{CO}_{2}\right.$, or $\left.\mathrm{H}_{2} \mathrm{O}\right)$, at atmospheric pressure. The agreement between results obtained in the two employed experimental reactors is certainly highly valuable and inspires considerable confidence of the reliability of results.

The experimental observations revealed several novel features of methane oxidation at intermediate temperatures in the presence of a high concentration of different bath gases: (i) Oscillatory regimes were established for almost all of the $\mathrm{CH}_{4} / \mathrm{O}_{2}$ considered mixtures in both of the reactors, when inlet temperatures are approximately between 1050 and 1250 K. (ii) The critical inlet temperature for the onset of temperature oscillations diminishes as the mixture equivalence ratio is gradually reduced. As the methane mole fraction is increased, the oscillation region on $\Phi-T_{\text {in }}$ maps widens under stoichiometric conditions but shrinks under fuel-lean conditions. (iii) When the equivalence ratio is increased above the stoichiometric value, temperature oscillations are no longer observed for $\mathrm{He}, \mathrm{N}_{2}$, and $\mathrm{N}_{2}-\mathrm{H}_{2} \mathrm{O}$ as bath gases, whereas for $\mathrm{CO}_{2}$-diluted mixtures, they also appear for fuel-rich conditions. (iv) $\mathrm{H}_{2} \mathrm{O}$ and $\mathrm{CO}_{2}$ lead to a general shift of the oscillation regions toward higher inlet temperatures with respect to $\mathrm{N}_{2}$ and He-diluted mixtures. (v) The waveforms, frequency, and amplitude of oscillations are strongly dependent upon inlet experimental conditions.

In summary, temperature oscillations occur when the reactor working temperature accesses a determined range. They strongly depend upon system intensive and extensive inlet parameters as well as reactor adiabatic features. The nature of the dynamic behavior is essentially related to the chemistry promoted under intermediate working temperatures.

Numerical analyses identified such kinetic features. They originate from the competition between methyl oxidation and recombination kinetic pathways and between low- and hightemperature branching reactions of the $\mathrm{H}_{2} / \mathrm{O}_{2}$ sub-system. The end of oscillations occurs at high temperatures when the inhibiting role of methyl recombination pathways is weakened by the promotion of different methane oxidation routes. It was found that bath gases can play a crucial role on the establishment of oscillations because of different heat capacities, thus different reactor working temperatures, and because of high collisional efficiencies in termolecular reactions, thus altering the relative importance of the identified competitive pathways responsible for temperature oscillations. A more fundamental definition of collisional efficiencies and their dependence upon the temperature and pressure would also be beneficial to improvements of existing kinetic models.

\section{ASSOCIATED CONTENT}

\section{S Supporting Information}

The Supporting Information is available free of charge on the ACS Publications website at DOI: 10.1021/acs.energyfuels.8b00967.

Photos of the JSFRs used and the thermocouple located inside the reactor, experimental data, and comparisons of model predictions to experimental measurements using different kinetic schemes (PDF)

\section{AUTHOR INFORMATION}

\section{Corresponding Author}

*Telephone: +39-0817682245. Fax: +39-0815936936. E-mail: m.lubranolavadera@irc.cnr.it.

ORCID 1

M. Lubrano Lavadera: 0000-0003-2173-4997

F. Battin-Leclerc: 0000-0001-8265-7492

Notes

The authors declare no competing financial interest.

\section{ACKNOWLEDGMENTS}

This work has received funding from the European Union H2020 (H2020-SPIRE-04-2016) under Grant Agreement 723706 and from the COST Action CM1404 "Chemistry of Smart Energy Carriers and Technologies".

\section{REFERENCES}

(1) Cavaliere, A.; de Joannon, M. Prog. Energy Combust. Sci. 2004, 30, 329-366.

(2) de Joannon, M.; Cavaliere, A.; Faravelli, T.; Ranzi, E.; Sabia, P.; Tregrossi, A. Proc. Combust. Inst. 2005, 30 (2), 2605-2612.

(3) Gray, P.; Griffiths, J. F.; Hasko, S. M.; Lignola, P.-G. Proc. R. Soc. London, Ser. A 1981, 374, 313-339.

(4) Griffiths, J. F.; Scott, S. K. Prog. Energy Combust. Sci. 1987, 13 (3), 161-197.

(5) Di Maio, F. P.; Lignola, P.-G.; Talarico, P. Combust. Sci. Technol. 1993, 91, 119-142.

(6) Skrumeda, L. L.; Ross, J. J. Phys. Chem. 1995, 99, 12835-12845.

(7) Griffiths, J. F. Prog. Energy Combust. Sci. 1995, 21, 25-107.

(8) Benson, S. W. Prog. Energy Combust. Sci. 1981, 7 (2), 125-134.

(9) Westbrook, C. K. Proc. Combust. Inst. 2000, 28, 1563-1577.

(10) Stoehr, K.-D.; Peters, N.; Beeckmann, J. Proc. Combust. Inst. 2015, 35, 3601-3607.

(11) Gray, P.; Griffiths, J. F.; Scott, S. K. Proc. R. Soc. London, Ser. A 1984, 394, 243-258.

(12) Chinnick, K.; Gibson, C.; Griffiths, J. F.; Kordylewski, W. Proc. R. Soc. London, Ser. A 1986, 405, 117-128.

(13) Chinnick, K.; Gibson, C.; Griffiths, J. F. Proc. R. Soc. London, Ser. A 1986, 405, 129-142. 
Energy \& Fuels

Article

(14) Baulch, D. L.; Griffiths, J. F.; Pappin, A. J.; Sykes, A. F. J. Chem. Soc., Faraday Trans. 1 1988, 84 (5), 1575-1586.

(15) Baulch, D. L.; Griffiths, J. F.; Johnson, B.; Richter, R. Proc. R. Soc. London, Ser. A 1990, 430, 151-166.

(16) Baulch, D. L.; Griffiths, J. F.; Kordylewski, W.; Richter, R. Philos. Trans. R. Soc., A 1991, 337, 199-210.

(17) Baulch, D. L.; Griffiths, J. F.; Richter, R. Proc. R. Soc. London, Ser. A 1991, 434, 399-412.

(18) Gray, P.; Griffiths, J. F.; Scott, S. K. Proc. R. Soc. London, Ser. A 1985, 397, 21-44.

(19) Griffiths, J. F.; Sykes, A. F. J. Chem. Soc., Faraday Trans. 1 1989, 85 (9), 3059-3069.

(20) Baulch, D. L.; Griffiths, J. F.; Richter, R. Chem. Eng. Sci. 1991, 46 (9), 2315-2322.

(21) de Joannon, M.; Sabia, P.; Tregrossi, A.; Cavaliere, A. Combust. Sci. Technol. 2004, 176 (5-6), 769-783.

(22) Sabia, P.; de Joannon, M.; Picarelli, A.; Ragucci, R. Combust. Flame 2013, 160 (1), 47-55.

(23) Dally, B. B.; Peters, N. Proceedings of the 6th Asia-Pacific Conference on Combustion; Nagoya, Japan, May 20-23, 2007.

(24) Wada, T.; Paczko, G.; Peters, N. Proceedings of the 4th European Combustion Meeting; Vienna, Austria, April 14-17, 2009.

(25) Sabia, P.; de Joannon, M.; Fierro, S.; Tregrossi, A.; Cavaliere, A. Exp. Therm. Fluid Sci. 2007, 31 (5), 469-475.

(26) Sabia, P.; Sorrentino, G.; Chinnici, A.; Cavaliere, A.; Ragucci, R. Energy Fuels 2015, 29, 1978-1986.

(27) Sun, Z.; Kota, A.; Sarsani, S.; West, D. H.; Balakotaiah, V. Chem. Eng. J. 2018, 343, 770-788.

(28) Bagheri, G.; Lubrano Lavadera, M.; Ranzi, E.; Pelucchi, M.; Sabia, P.; de Joannon, M.; Parente, A.; Faravelli, T. Combust. Sci. Technol. 2018, 1-13.

(29) Herbinet, O.; Battin-Leclerc, F. Int. J. Chem. Kinet. 2014, 46 (10), 619-639.

(30) Matras, D.; Villermaux, J. Chem. Eng. Sci. 1973, 28 (1), 129137.

(31) David, R.; Matras, D. Can. J. Chem. Eng. 1975, 53, 297-300.

(32) Levenspiel, O. Chemical Reaction Engineering; John Wiley and Sons, Inc.: New York, 1958; Chapter 9, pp 280-284.

(33) Cuoci, A.; Frassoldati, A.; Faravelli, T.; Ranzi, E. Comput. Phys. Commun. 2015, 192, 237-264.

(34) David, R.; Houzelot, J. L.; Villermaux, J. Chem. Eng. Sci. 1979, 34 (6), 867-876.

(35) Ranzi, E.; Cavallotti, C.; Cuoci, A.; Frassoldati, A.; Pelucchi, M.; Faravelli, T. Combust. Flame 2015, 162 (5), 1679-1691.

(36) Lubrano Lavadera, M.; Sabia, P.; Sorrentino, G.; Ragucci, R.; de Joannon, M. Fuel 2016, 184, 876-888.

(37) Lubrano Lavadera, M.; Sabia, P.; de Joannon, M.; Cavaliere, A.; Ragucci, R. Exp. Therm. Fluid Sci. 2018, 95, 35-43.

(38) Reaction Design. Chemkin-Pro 15131; Reaction Design: San Diego, CA, 2013.

(39) Afarin, Y.; Tabejamaat, S.; Mardani, A. Proceedings of the 7th Mediterranean Combustion Symposium; Cagliari, Italy, Sept 11-15, 2011.

10099

DOI: 10.1021/acs.energyfuels.8b00967

Energy Fuels 2018, 32, 10088-10099 